\title{
Structural, Thermal and Magnetic Properties of Ga Excess Ni-Mn-Ga
}

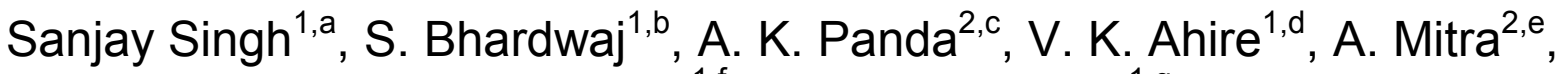 \\ A. M. Awasthi, ${ }^{1, f}$ and S. R. Barman ${ }^{1, g}$ \\ ${ }^{1}$ UGC-DAE Consortium for Scientific Research, Khandwa Road, Indore 452001, Madhya \\ Pradesh, India. \\ ${ }^{2}$ National Metallurgical Laboratory, Jamshedpur 831007, India \\ asanju@csr.ernet.in, bsuresh@csr.ernet.in, 'akpanda@nmlindia.org, 'vkahire@csr.ernet.in, \\ eamitra@nmlindia.org, ${ }^{\mathrm{f}}$ amawasthi@csr.ernet.in, ${ }^{9}$ barmansr@gmail.com
}

Keywords: Ferromagnetic shape memory alloys, $\mathrm{x}$-ray diffraction, martensitic transition.

\begin{abstract}
The martensitic transition and the ferro- to paramagnetic transition have been studied in a series of $\mathrm{Ga}$ excess $\mathrm{Ni}-\mathrm{Mn}-\mathrm{Ga}$ specimens $\left[\mathrm{Ni}_{2-\mathrm{x}} \mathrm{MnGa}_{1+\mathrm{x}}(0.4 \leq \mathrm{x} \leq 0.9)\right]$ by differential scanning calorimetry and magnetization measurements. The martensitic transition exhibits a hysteresis whose width is similar to $\mathrm{Ni}_{2} \mathrm{MnGa}$, indicating that the transition is thermoelastic. The latent heat of transformation is comparable with other Ni-Mn-Ga alloys. A substantial increase in the martensitic transition temperature is observed due to Ga doping. Interestingly, the x-ray diffraction pattern of all the compositions studied show a modulated martensitic structure in the martensitic phase.
\end{abstract}

\section{Introduction}

Ferromagnetic shape memory alloy (FSMA) $\mathrm{Ni}_{2} \mathrm{MnGa}$ has a potential for practical applications due to its large magnetic field induced strain (MFIS) [1]. $\mathrm{Ni}_{2} \mathrm{MnGa}$ shows ferromagnetic as well as structural transition from high temperature cubic austenitic phase to low temperature martensitic phase. The modulation observed in the crystal structure of Ni-Mn-Ga in the martensitic phase influences the MFIS, since MFIS has been observed only for the modulated structures [2]. Largest MFIS of $10 \%$ at field about 1 Tesla has been reported for $\mathrm{Ni}_{1.95} \mathrm{Mn}_{1.19} \mathrm{Ga}_{0.86}$ that exhibits seven layer modulated structure in the martensitic phase [3]. However, the low structural and magnetic transition temperatures and brittleness of $\mathrm{Ni}_{2} \mathrm{MnGa}$ are shortcomings for its practical high temperature applications. Thus, in last few years a considerable amount of work has been performed to overcome these problems. For example, off-stoichiometric Ni-Mn-Ga and different other ferromagnetic shape memory alloys like Fe-Pt, Fe-Pd, Co-Ni-Al, Mn-Ni-In have been investigated [4-9]. It has been reported that addition of Fe in place of $\mathrm{Mn}$ in Ni-Mn-Ga improves the ductility of the alloy [10] and MFIS of 5.5\% was obtained [11]. Small MFIS of $0.17 \%$ has been reported for $\mathrm{Ni}-\mathrm{Mn}-\mathrm{Al}$ and its martensitic transition temperature is below room temperature [12]. Structural and magnetic properties of non-stoichiometric Ni-Mn-In and Ni-Mn-Sn have been studied [13]. However, these alloys have not turned out to be viable alternatives for Ni-Mn-Ga. Therefore, it is still an important challenge to search for materials having properties that are better than Ni-Mn-Ga. Recently, we have proposed by total energy calculations based on density functional theory, differential scanning calorimetry and $\mathrm{x}$-ray diffraction that $\mathrm{Ga}_{2} \mathrm{MnNi}$ could possibly exhibit ferromagnetic shape memory effect with highest $\mathrm{T}_{M}$ in Ni-Mn-Ga series [14]. The importance of $\mathrm{Ga}$ in making $\mathrm{Ni}_{2} \mathrm{MnGa}$ a FSMA is clear from the fact that related stoichiometric alloys such as $\mathrm{Ni}_{2} \mathrm{MnAl}, \mathrm{Ni}_{2} \mathrm{MnIn}$ and $\mathrm{Ni}_{2} \mathrm{MnSn}$ do not exhibit martensitic transition. So, here we report a detailed study of $\mathrm{Ga}$ excess $\mathrm{Ni}-\mathrm{Mn}-\mathrm{Ga}$ compositions $\left[\mathrm{Ni}_{2-\mathrm{x}} \mathrm{MnGa}_{1+\mathrm{x}}(0.4 \leq \mathrm{x} \leq 0.9)\right]$ to study the evolution of physical properties (for example the crystal structure, the magnetic properties and the transition temperatures) from $\mathrm{Ni}_{2} \mathrm{MnGa}$ to $\mathrm{Ga}_{2} \mathrm{MnNi}$ [14]. 


\section{Experimental methods}

The polycrystalline ingots of $\mathrm{Ni}_{2-\mathrm{x}} \mathrm{MnGa}_{1+\mathrm{x}}(0.4 \leq \mathrm{x} \leq 0.9)$ have been prepared by melting appropriate quantities of $\mathrm{Ni}, \mathrm{Mn}$ and $\mathrm{Ga}$ with $99.99 \%$ purity in an arc furnace under inert argon atmosphere. The ingots were subsequently annealed at $873 \mathrm{~K}$ for 12 days and at $723 \mathrm{~K}$ for 1 day for homogenization and then slowly cooled down to room temperature [13]. Energy dispersive analysis of x-rays has been used to determine the composition. The powder XRD data at room temperature were obtained with $\mathrm{Cu} \mathrm{K} \alpha$ radiation using a Rigaku X-ray diffractometer (RUH3R). The data were recorded at the rate of $2^{\circ} / \mathrm{min}$ with step size of $0.02^{\circ}$. For XRD, pieces cut from the ingot were manually ground to powder. Differential scanning calorimetry (DSC) measurements were performed using Model 2910 from TA Instruments. Magnetization was performed using vibrating sample magnetometers from Oxford Instruments and Lake Shore Cryotronics.
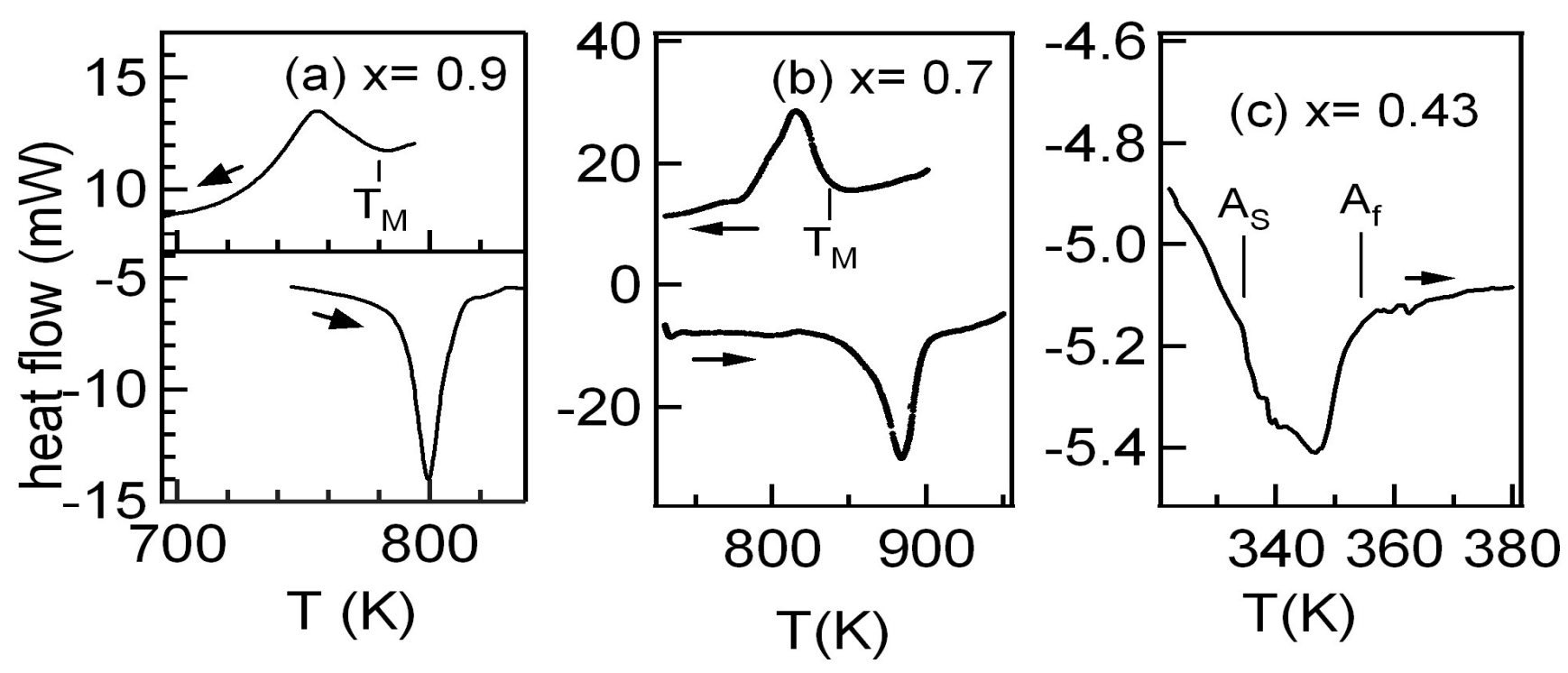

Fig. 1: Differential scanning calorimetry showing the martensitic transition in $\mathrm{Ni}_{2-\mathrm{x}} \mathrm{MnGa}_{1+\mathrm{x}}$ for (a) $x=0.9$ and $(b) x=0.7$ (c) $x=0.43$. Arrows indicate the heating and cooling directions.

\section{Results and discussion}

Differential scanning calorimetry measurements on $\mathrm{Ni}_{2-\mathrm{x}} \mathrm{MnGa}_{1+\mathrm{x}}(0.4 \leq \mathrm{x} \leq 0.9)$ clearly show the first order nature of the transition and the four temperatures [martensitic start $\left(\mathrm{T}_{\mathrm{M}}\right)$, martensitic finish $\left(\mathrm{T}_{\mathrm{Mf}}\right)$, austenitic start $\left(\mathrm{T}_{\mathrm{As}}\right)$, and austenitic finish $\left.\left(\mathrm{T}_{\mathrm{Af}}\right)\right]$. For $\mathrm{Ni}_{1.02} \mathrm{Mn}_{1.08} \mathrm{Ga}_{1.9}(\mathrm{x}=0.9)$, the transition temperatures $\mathrm{T}_{\mathrm{M}}, \mathrm{T}_{\mathrm{Mf}}, \mathrm{T}_{\mathrm{As}}$ and $\mathrm{T}_{\mathrm{Af}}$ are $780,732,789$, and 811 , respectively. For $\mathrm{Ni}_{1.3 \mathrm{Mn}}$ $\mathrm{Ga}_{1.7}(\mathrm{x}=0.7)$ these temperatures are $838,781,855$, and $900 \mathrm{~K}$, respectively. For $\mathrm{Ni}_{1.5} \mathrm{Mn}_{1.07} \mathrm{Ga}_{1.43}$, the $\mathrm{T}_{\mathrm{As}}$ and $\mathrm{T}_{\mathrm{Af}}$ are 333 and $351 \mathrm{~K}$, respectively. The width of the hysteresis, defined as the difference between $\left(\mathrm{T}_{\mathrm{As}}+\mathrm{T}_{\mathrm{Af}}\right) / 2$ and $\left(\mathrm{T}_{\mathrm{M}}+\mathrm{T}_{\mathrm{Mf}}\right) / 2$ [5], are 68 and $44 \mathrm{~K}$ for $\mathrm{x}=0.7$ and 0.9 , respectively. The relatively small width of hysteresis show that the transition is thermoelastic in nature. The latent heat of transformation turns out to be $0.15,1.5$ and $2.35 \mathrm{~kJ} / \mathrm{mole}$, and for $\mathrm{x}=$ $0.43,0.7$ and 0.9 , respectively. Thus, with increase in Ga content, the latent heat increases.

The room temperature powder XRD patterns of $\mathrm{Ni}_{2-\mathrm{x}} \mathrm{MnGa}_{1+\mathrm{x}}(0.43 \leq \mathrm{x} \leq 0.9)$ show that all the samples are martensitic. The XRD data have been analyzed by Lebail fitting procedure [16]. We find that $\mathrm{Ni}_{1.02} \mathrm{Mn}_{1.08} \mathrm{Ga}_{1.9}$ shows a monoclinic structure with lattice parameters $\mathrm{a}=4.31 \AA, \mathrm{b}=29.51$ $\AA, c=5.55 \AA, \beta=90.49^{\circ} . \mathrm{Ni}_{1.3} \mathrm{Mn} \mathrm{Ga}_{1.7}$ also exhibits a monoclinic structure with lattice parameters $\mathrm{a}=4.25 \AA, \mathrm{b}=29.56 \AA, \mathrm{c}=5.57 \AA, \beta=90.94^{\circ}$. Thus, for both $\mathrm{Ni}_{1.02} \mathrm{Mn}_{1.08} \mathrm{Ga}_{1.9}$ and $\mathrm{Ni}_{1.3} \mathrm{Mn} \mathrm{Ga}_{1.7}$ $\mathrm{b} \sim 7 \mathrm{a}$, which is indicative of the occurrence of $7 \mathrm{M}$ modulation. In contrast, $\mathrm{Ni}_{1.5} \mathrm{Mn}_{1.07} \mathrm{Ga}_{1.43}$ shows 
a monoclinic structure where $\mathrm{b} \sim 5 \mathrm{a}$ that is indicative of $5 \mathrm{M}$ modulation with lattice parameters $\mathrm{a}=$ $4.18 \AA, b=21.06 \AA, c=5.57 \AA, \beta=90.51^{\circ}$. The $5 \mathrm{M}$ and $7 \mathrm{M}$ modulation have been also observed in $\mathrm{Ni}$ and $\mathrm{Mn}$ excess Ni-Mn-Ga [17-20]. The XRD results thus show that all samples $\mathrm{Ni}_{2-\mathrm{x}} \mathrm{MnGa}_{1+\mathrm{x}}$ $(0.43 \leq \mathrm{x} \leq 0.9)$ studied here have monoclinic modulated structure in the martensitic phase. Existence of modulation makes the Ga excess Ni-Mn-Ga a good candidate to show magnetic field induced strain $[2,3]$ since it has been reported that modulated structures have lower twinning stress and hence are expected to exhibit twin boundary motion [21]. It has been reported in literature that the twinning stress is less if $\beta$ is close to $90^{\circ}$ [22]. Here for all samples, $\beta$ is indeed close to $90^{\circ}$ and thus the twinning stress is expected to be less.

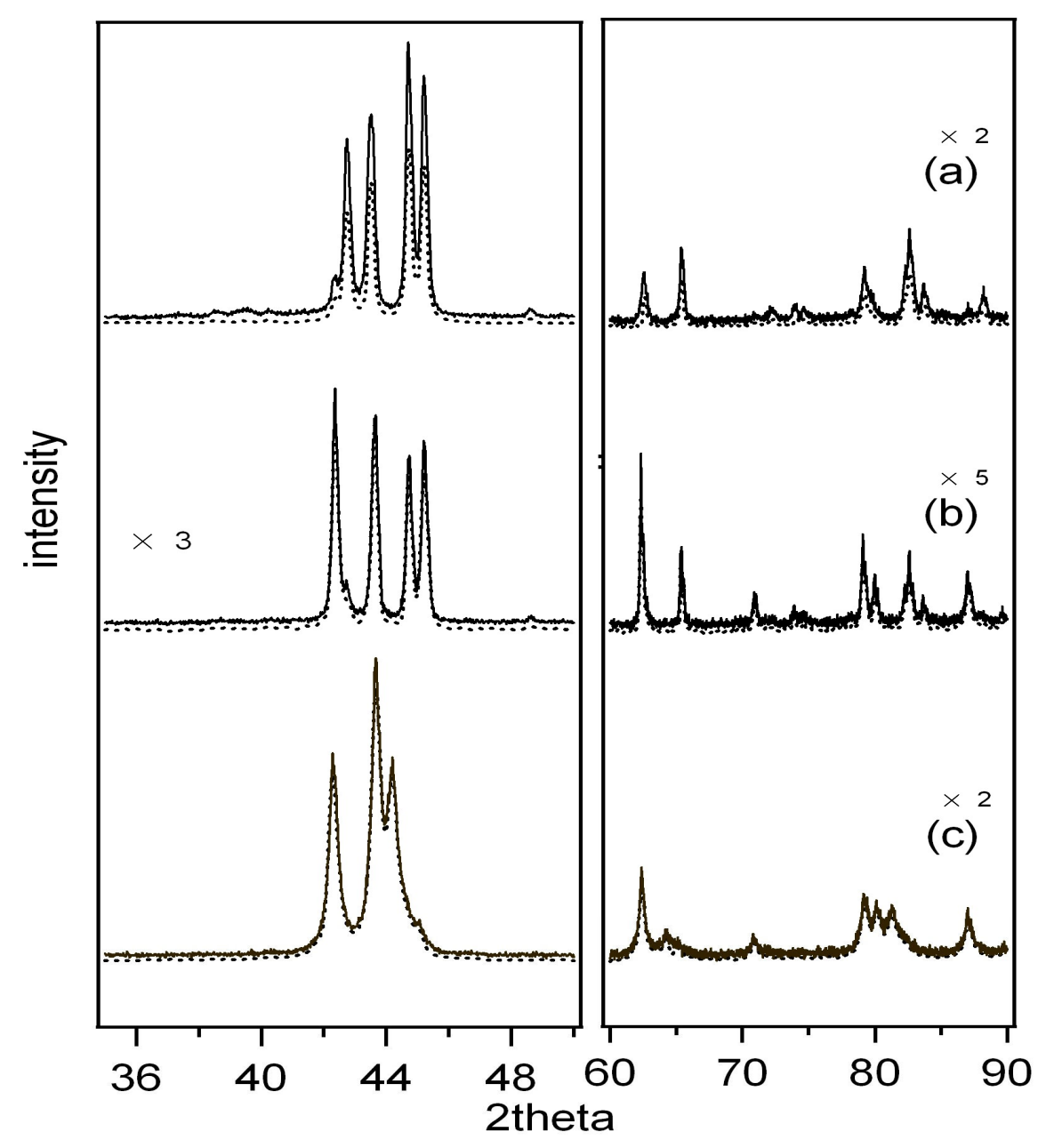

Fig. 2: X-ray diffraction pattern (solid line) of $\mathrm{Ni}_{2-\mathrm{x}} \mathrm{MnGa}_{1+\mathrm{x}}(0.43 \leq \mathrm{x} \leq 0.9$ ) for different $\mathrm{x}$ at room temperature. (a) $x=0.9$ and (b) $x=0.7$ (c) $x=0.43$. The calculated profiles obtained by Lebail refinement are shown by dashed lines.

Fig. 3 shows the magnetization $(\mathrm{M})$ as a function of temperature and the transition temperatures as a function of composition. The magnetization data have been taken in a low applied field of 10 Gauss. Expectedly, all the $\mathrm{M}(\mathrm{T})$ curves show sharp decrease in magnetization at $\mathrm{T}_{\mathrm{C}}$. For $\mathrm{x}=0.9$ and $\mathrm{x}=0.7$ samples, the magnetic transition takes place in the martensitic state and for $\mathrm{x}=0.43$ the magnetic and structural transition temperatures almost coincide. $\mathrm{T}_{\mathrm{C}}$ is found to decrease with increasing $\mathrm{x}$ in $\mathrm{Ni}_{2-\mathrm{x}} \mathrm{MnGa}_{1+\mathrm{x}}$. For $\mathrm{Ni}_{2} \mathrm{MnGa}(\mathrm{x}=0), \mathrm{T}_{\mathrm{C}}$ is $378 \mathrm{~K}$ and it decreases to $330 \mathrm{~K}$ for 
$\mathrm{NiMn}_{1.08} \mathrm{Ga}_{1.9}$. From Fig. 3(d), it is clear that $\mathrm{T}_{\mathrm{M}}$ and $\mathrm{T}_{\mathrm{C}}$ follow opposite trend, which is in agreement with previous studies done on $\mathrm{Ni}$ excess $\mathrm{Ni}-\mathrm{Mn}-\mathrm{Ga}$ where $\mathrm{T}_{\mathrm{C}}$ is found to decrease with increasing $T_{M}[5] . T_{M}$ and $T_{C}$ almost merge for $x=0.43$, which might be an interesting composition for further study.
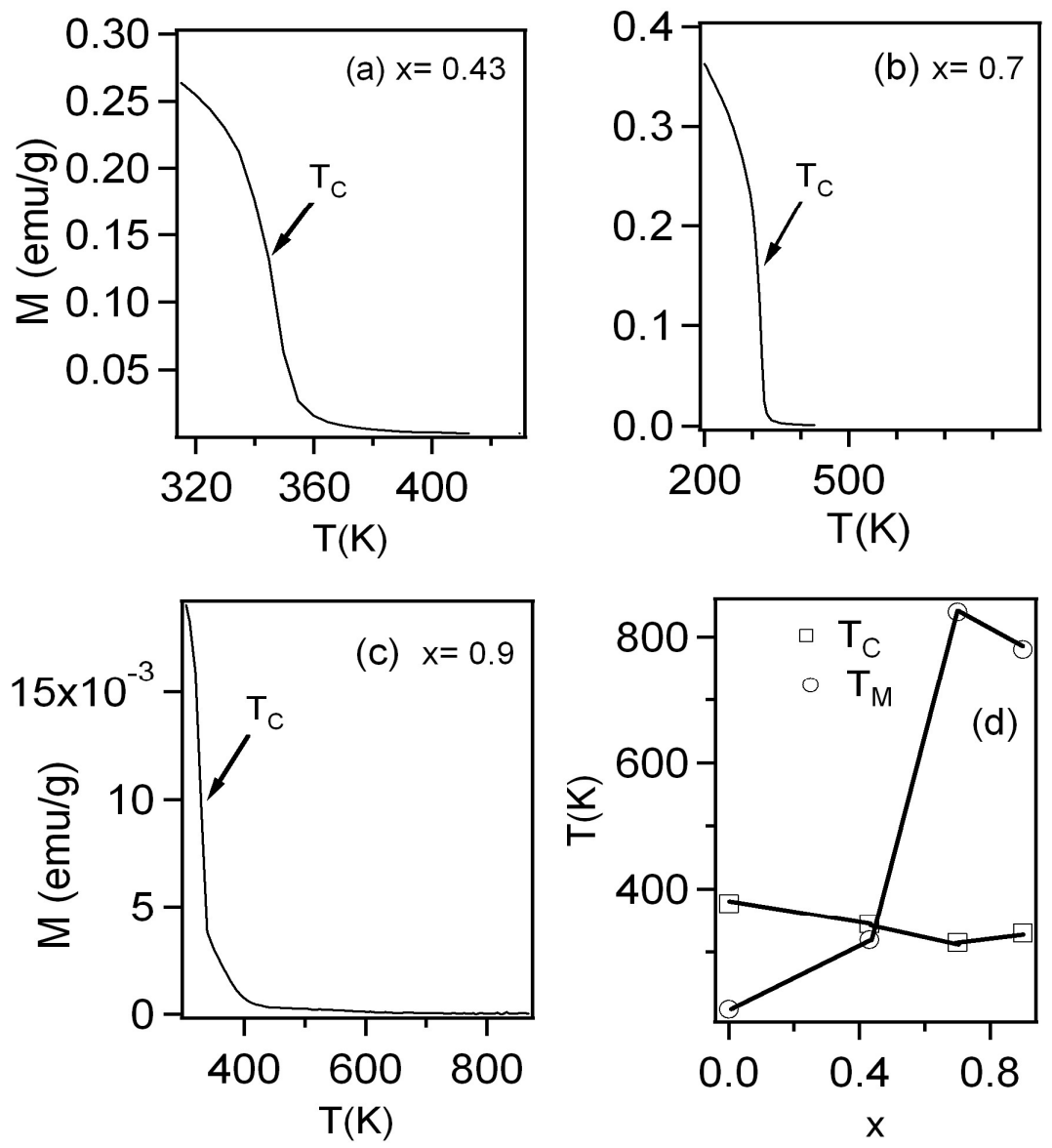

Fig. 3: $M$ vs $T$ and variation of $T_{M}$ and $T_{C}$ for $\mathrm{Ni}_{2-x} \mathrm{MnGa}_{1+x}(0.4 \leq x \leq 0.9)$. (a) $x=0.43$ (b) 0.7 (c) 0.9 (d) $T_{M}$ and $T_{C}$ as a function of $x$.

\section{Summary}

The crystal structure at room temperature, the martensitic and magnetic transition temperatures have been studied for $\mathrm{Ni}_{2-\mathrm{x}} \mathrm{MnGa}_{1+\mathrm{x}}(0.43 \leq \mathrm{x} \leq 0.9)$ as a function of $\mathrm{x}$. From the Lebail fitting of $\mathrm{x}$-ray diffraction, we find that $\mathrm{Ni}_{1.02} \mathrm{Mn}_{1.08} \mathrm{Ga}_{1.9}$ and $\mathrm{Ni}_{1.3} \mathrm{Mn} \mathrm{Ga}_{1.7}$ show $7 \mathrm{M}$ modulated monoclinic structure, while $\mathrm{Ni}_{1.5} \mathrm{Mn}_{1.07} \mathrm{Ga}_{1.43}$ shows $5 \mathrm{M}$ monoclinic modulation at room temperature. DSC shows that $\mathrm{T}_{\mathrm{M}}$ is higher for these samples compared to Ni and Mn excess Ni-Mn-Ga. Magnetization shows that $\mathrm{T}_{\mathrm{C}}$ decreases with increasing $\mathrm{x}$.

\section{References}

[1] K. Ullakko, J. K. Huang, C. Kantner, R. C. O’Handley, and V. V. Kokorin, Appl. Phys. Lett. 69, 1966 (1996).

[2] S. J. Murray, M. Marioni, S. M. Allen, R. C. O’Handley, T. A. Lograsso, Appl. Phys. Lett. 77, $886(2000)$. 
[3] A. Sozinov, A. A. Likhachev, N. Lanska and K. Ullakko, Appl. Phys. Lett. 80, 1746 (2002).

[4] A. N. Vasilev, A. D. Bozhko, V. V. Khovailo, I. E. Dikshtein, V. G. Shavrov, V. D. Buchelnikov, M. Matsumoto, S. Suzuki, T. Takagi and J. Tani, Phys. Rev. B 59, 1113 (1999).

[5] S. Banik, A. Chakrabarti, U. Kumar, P. K. Mukhopadhyay, A. M. Awasthi, R. Ranjan, J. Schneider, B. L. Ahuja, and S. R. Barman, Phys. Rev. B 74, 085110 (2006); B. L. Ahuja, B. K. Sharma, S. Mathur, N. L. Heda, M. Itou, A. Andrejczuk, Y. Sakurai, A. Chakrabarti, S. Banik, A. M. Awasthi, and S. R. Barman, Phys. Rev. B 75, 134403 (2007); A. Chakrabarti and S. R. Barman, Appl. Phys. Lett. 94, 161908 (2009).

[6] G. D. Liu, J. L. Chen, Z. H. Liu, X. F. Dai, G. H. Wu, B. Zhang, X. X. Zhang, Appl. Phys. Lett. 87, 262504 (2005).

[7] T. Kakeshita, T. Takeuchi, T. Saburi, R. Oshima, S. Muto, Appl. Phys. Lett. 77, 1502 (2000).

[8] T. Sakamoto, T. Fukuda, and T. Kakeshita, T. Takeuchi, K. Kishio, J. Appl. Phys. 93, 8647 (2003).

[9] K. Oikawa, L. Wulff, T. Iijima, F. Gejima, T. Ohmori, A. Fujita, K. Fukamichi, R. Kainuma, and K. Ishida, Appl. Phys. Lett. 79, 3290 (2001).

[10] H. B. Wang, F. Chen, Z. Y. Gao, W. Cai, L. C. Zhao, Mat. Sci. Eng. A 438, 990 (2006).

[11] K. Koho, O. Soderberg, N. Lanska, Y. Ge, X. Liu, L. Straka, J. Vimpari, O. Heczko, V. K. Lindroos, Mat. Sci. Eng. A 378, 384 (2004).

[12] A. Fujita, K. Fukamichi, F. Gejima, R. Kainuma, and K. Ishida, Appl. Phys. Lett. 77, 3054 (2000).

[13] T. Krenke, M. Acet, E. F. Wassermann, X. Moya, L. Mañosa, and A. Planes, Phys. Rev. B 73, 174413 (2006).

[14] S. R. Barman, A. Chakrabarti, S. Singh, S. Banik, S. Bhardwaj, P. L. Paulose, B. A. Chalke, A. K. Panda, A. Mitra, and A. M. Awasthi, Phys. Rev. B 78, 134406 (2008).

[15] S. Banik, R. Ranjan, A. Chakrabarti, S. Bhardwaj, N. P. Lalla, A. M. Awasthi, V. Sathe, D. M. Phase, P. K. Mukhopadhyay, D. Pandey, and S. R. Barman Phys. Rev. B 75, 104107 (2007).

[16] A. Le Bail, H. Duroy, and J. L. Fourquet, Mater. Res. Bull. 23, 447 (1988).

[17] Y. Ge, A. Sozinov, O. Soderberg, N. Lanska, K. Ullakko and V. K. Lindroos, Journal de Physique IV 112, 921 (2003).

[18] L. Righi, F. Albertini, L. Pareti, A. Paoluzi, G. Calestani, Acta. Mater. 55, 5237 (2007).

[19] J. Pons, V. A. Chernenko, R. Santamarta, and E. Cesari, Acta Mater. 48, 3027 (2000).

[20] R. Ranjan, S. Banik, S. R. Barman, U. Kumar, P. K. Mukhopadhyay, and D. Pandey, Phys. Rev. B 74, 224443 (2006); R. Ranjan, S. Singh, H. Boysen, D. Trots, S. Banik, A. M. Awasthi, P. K. Mukhopadhyay, and S. R. Barman, J. Appl. Phys. 106, 033510 (2009).

[21] A. A. Likhachev, A. Sozinov and K. Ullakko, Mater. Sci. Eng., A 378, 513 (2004).

[22] R. Kainuma, F. Gejima, Y. Suoto, I. Ohnuma and K. Ishuda, Mater. Trans., JIM 41, 943 (2000). 